\title{
Generation of Alkoxyl Radicals from $N$-Alkoxy-2-pyridones
}

\author{
Eunae Kim, Chang Ho Cho, and Sunggak Kim*
}

Department of Chemistry and Center for Molecular Design \& Synthesis, School of Molecular Science (BK21), Korea Advanced Institute of Science and Technology, Daejeon 305-701, Korea. *E-mail: skim@kaist.ac.kr Received August 31, 2005

Key Words : Radical, Alkoxyl radical, $N$-Alkoxy-2-pyridone, Alcohol

Alkoxyl radicals have unique characteristic properties such as a facile $\beta$-fragmentation ${ }^{1}$ and a hydrogen abstraction $^{2}$ due to their high reactivity. Various alkoxyl radical precursors are normally prepared from alcohols and include nitrites, ${ }^{3}$ nitrates, ${ }^{4}$ hypohalites, ${ }^{5}$ sulfenyl ethers, ${ }^{6}$ and $N$ alkoxyphthalimides., ${ }^{7,8}$ Especially, $N$-alkoxypyridine-2thiones 3 have attracted a great deal of attention as synthetically useful alkoxyl radical precursors. ${ }^{9}$ However, preparations of $\mathrm{N}$-alkoxypyridine-2-thiones $\mathbf{3}$ are problematic due to competing $O$ - and $S$-alkylation (eq. 1). ${ }^{10}$ Even under carefully controlled conditions, the desired product 3 is normally obtained in poor yields with a significant amount of undesired $S$-alkylated side product 4 . In addition, the radical precursor is also unstable in light. Thus, some improved procedures have been reported, but the chemical yields were not very high. ${ }^{11}$ Since radical precursors are needed to be stable for safe handling and better chemical yields, we have been interested in $N$-alkoxy-2-pyridones 5 as new alkoxyl radical precursors.

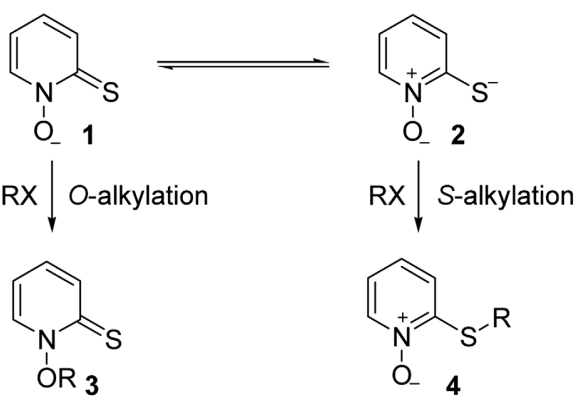

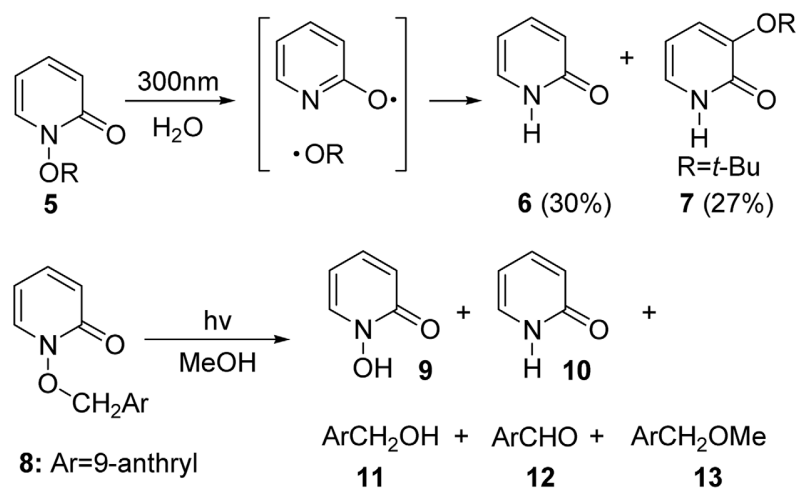

It has been known that $N$-alkoxy-2-pyridones 5 are photochemically decomposed through $\mathrm{N}-\mathrm{O}$ bond cleavage to give the parent pyridone 6 and the 3-alkoxy-2-pyridone 7 along with the recovered starting material 5 (30\%) (eq. 2). ${ }^{12}$ In the case of $\mathrm{N}$-arylmethyloxy-2-pyridone 8, the heterolytic $\mathrm{C}-\mathrm{O}$ bond cleavage is also observed together with the homolytic N-O bond cleavage (eq. 3). ${ }^{13}$ Furthermore, the acyl derivatives of $N$-hydroxy-2-pyridone can be utilized as a source of carbon radicals. ${ }^{14}$ We have studied the efficiency and the scope of generation of alkoxyl radicals from $\mathrm{N}$ alkoxy-2-pyridones $\mathbf{5}$ using tributyltin hydride and AIBN. ${ }^{15}$

$N$-Alkoxy-2-pyridones $\mathbf{5}$ could be conveniently prepared from $N$-hydroxy-2-pyridone $(9)^{16}$ by routine operations using alkyl halides or alcohols. First, treatment of sodium salt of 9 with alkyl halide 14 in DMF at $60{ }^{\circ} \mathrm{C}$ for several hours gave $\mathbf{5}$ in high yields (method A). Secondly, $\mathbf{5}$ were conveniently prepared by treatment of alcohols 15 with 9 ,

Table 1. Preparation of $N$-Alkoxy-2-pyridones and Generation of Alkoxyl Radicals

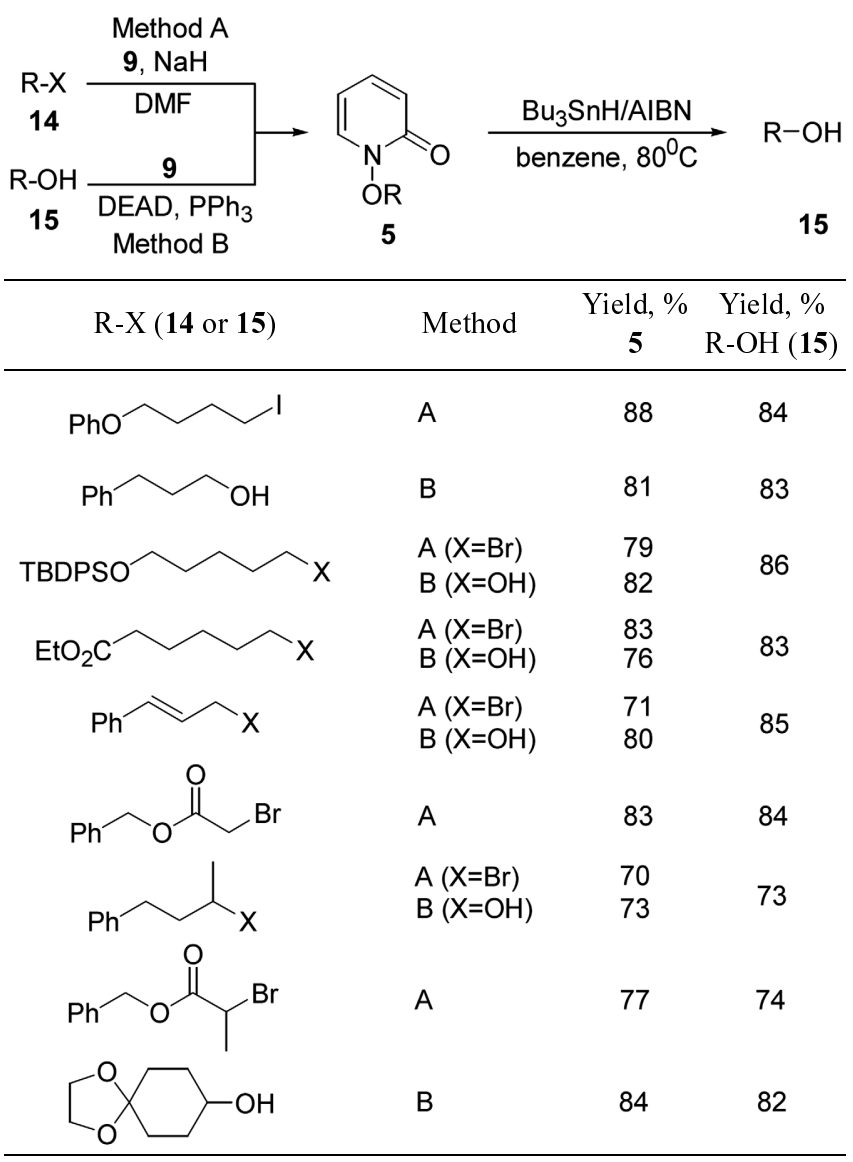




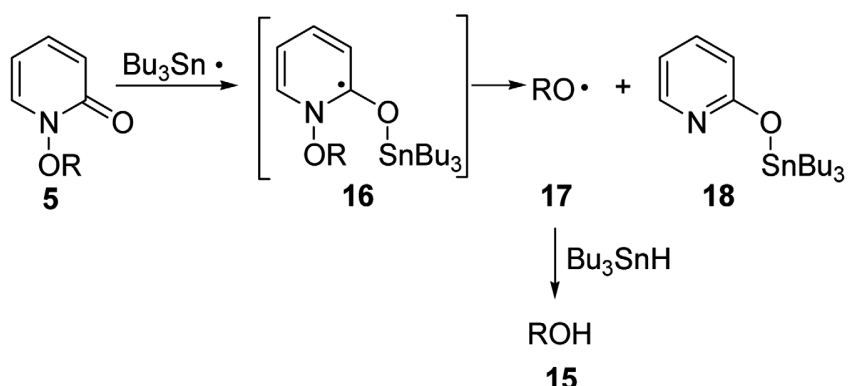

Scheme 1

diethyl azodicarboxylate, and triphenylphosphine in THF using Mitsunobu method (method B).

Two methods were equally effective and worked well with primary, secondary, allylic, and benzylic substrates. As we expected, $N$-alkoxy-2-pyridones $\mathbf{5}$ were very stable on silica gel and on heating, and could be kept for several weeks without any decomposition. The experimental results for the preparation of $\mathbf{5}$ are summarized in Table 1.

As shown in Scheme 1, generation of alkoxyl radical 17 would be initiated by the attack of tributyltin radical onto the carbonyl oxygen and followed by the cleavage of $\mathrm{N}-\mathrm{O}$ bond to generate the alkoxyl radical 17. Treatment of 5 with $n$ $\mathrm{Bu}_{3} \mathrm{SnH}$ (1.5 equiv.) and $\mathrm{AIBN}$ as initiator in refluxing benzene for 6-8 h gave the corresponding alcohols in high yield. Table 1 summarizes experimental results and shows the clean generation of alkoxyl radicals from $\mathbf{5}$. It is noteworthy that the reactivity of $N$-alkoxy-2-pyridones $\mathbf{5}$ toward tributyltin radical was lower than that of aryl bromide group. When the radical reaction was carried out with $N$-(4-bromo-benzyloxy)-2-pyridone (19) under the same condition, the bromide group was selectively reduced to yield 20 (71\%), whereas benzyl alcohol was obtained in $70 \%$ yield using an excess amount of $n-\mathrm{Bu}_{3} \mathrm{SnH}$ (3.0 equiv.) (eq. 4). Radical reaction of 21 with $n-\mathrm{Bu}_{3} \mathrm{SnH}$ and $\mathrm{AIBN}$ for $5 \mathrm{~h}$ gave 2-benzyltetrahydrofuran (22) in $75 \%$ yield via 5 exo ring closure of the alkoxyl radical intermediate (eq. 5).
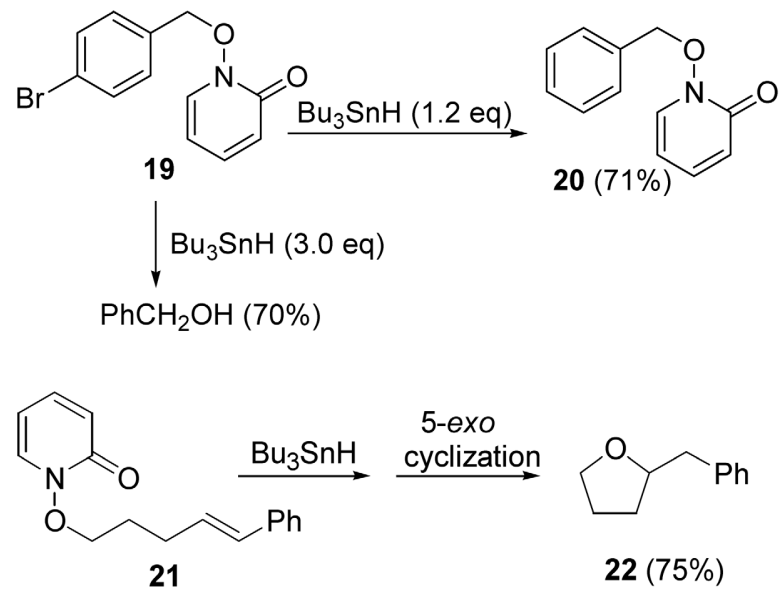

We have studied the efficiency of 1,5-hydrogen transfer from carbon to oxygen using 23 . The radical reaction of $\mathbf{2 3}$
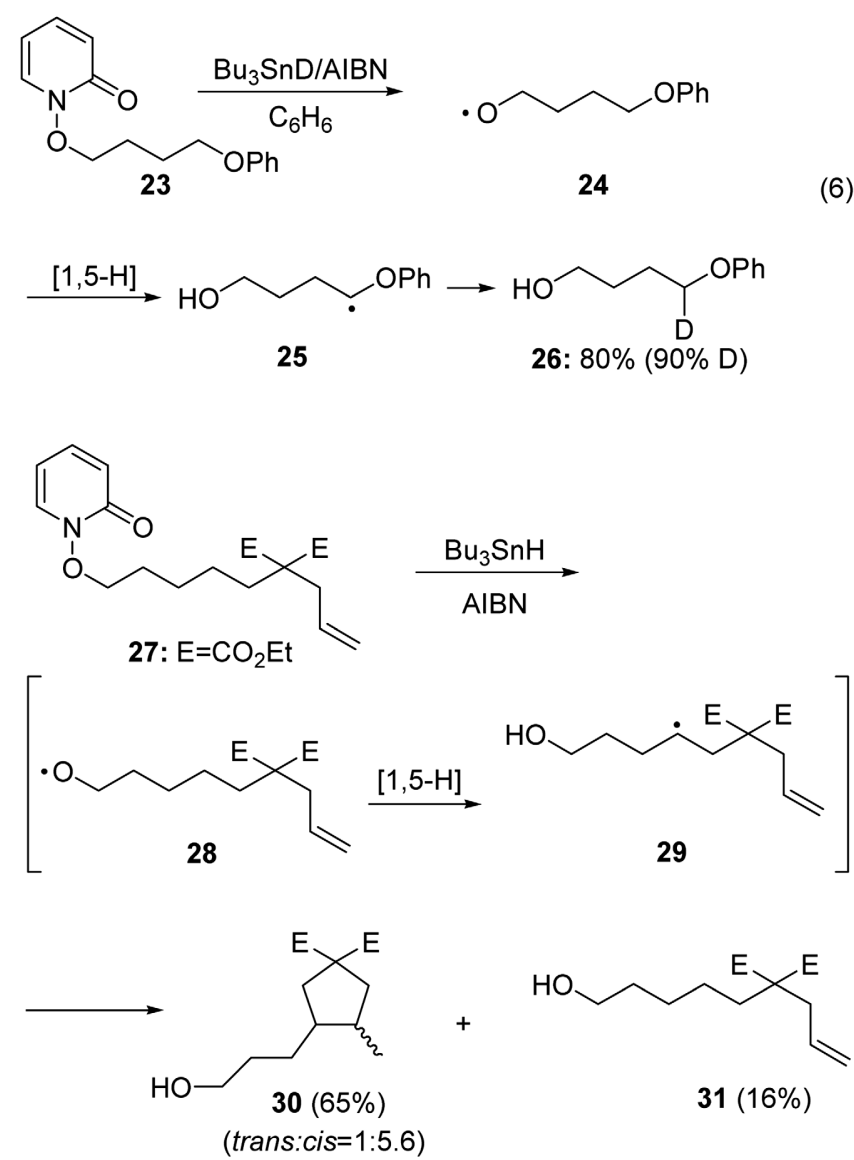

Scheme 2

with $n-\mathrm{Bu}_{3} \mathrm{SnD}$ (1.5 equiv.) and $\mathrm{AIBN}$ (0.2 equiv.) in refluxing benzene $(0.05 \mathrm{M})$ under a high dilution afforded 26 in $80 \%$ yield with $90 \%$ deuterium exchange (eq. 6). As extension of this work, we studied the possibility of a sequential reaction involving 1,5-hydrogen atom transfer and subsequent cyclization. When the radical reaction of 27 was performed under the similar condition, the desired product 30 was isolated in $65 \%$ yield along with the direct reduction product $\mathbf{3 1}$ in 16\% yield (Scheme 2). Evidently, 1,5-hydrogen transfer was followed by the cyclization of an alkyl radical 29 to double bond to provide $\mathbf{3 0}$.

In conclusion, we have shown that readily available and stable $\mathrm{N}$-alkoxy-2-pyridones are useful precursors of alkoxyl radicals and can complement the existing methods.

\section{Experimental Section}

General procedure for the synthesis of $\mathbf{N}$-alkoxy-2pyridones 5. Method A: To a solution of sodium hydride (26 mg, $0.65 \mathrm{mmol})$ in dry DMF $(1.5 \mathrm{~mL})$ was added $N$ hydroxy-2-pyridone $(9,56 \mathrm{mg}, 0.5 \mathrm{mmol})$ at $0{ }^{\circ} \mathrm{C}$, and stirred for $1 \mathrm{~h}$ at room temperature. After the addition of 4phenoxybutyl iodide (189 $\mathrm{mg}, 0.65 \mathrm{mmol})$, the mixture was stirred for $12 \mathrm{~h}$ at $60{ }^{\circ} \mathrm{C}$ and then diluted with water and extracted with ethyl acetate. The organic layer was dried over anhydrous $\mathrm{MgSO}_{4}$, filtered and concentrated under reduced pressure. The residue was purified by silica gel 
column chromatography (ethyl acetate $/ n$-hexane $=1 / 1$ ) to give $\mathrm{N}$-(4-phenoxy-butoxy)-2-pyridone $\left(\mathbf{5}, \mathrm{RO}=\mathrm{PhO}\left(\mathrm{CH}_{2}\right)_{4} \mathrm{O}\right.$, $114 \mathrm{mg}, 88 \%) .{ }^{1} \mathrm{H}$ NMR (300 MHz, $\left.\mathrm{CDCl}_{3}\right) \delta 1.86-2.02(\mathrm{~m}$, $4 \mathrm{H}), 4.02(\mathrm{t}, J=5.4 \mathrm{~Hz}, 2 \mathrm{H}), 4.32(\mathrm{t}, J=5.4 \mathrm{~Hz}, 2 \mathrm{H}), 6.07-$ $6.12(\mathrm{~m}, 1 \mathrm{H}), 6.62-6.67(\mathrm{~m}, 1 \mathrm{H}), 6.86-6.94(\mathrm{~m}, 3 \mathrm{H}), 7.23-$ $7.30(\mathrm{~m}, 3 \mathrm{H}), 7.46-7.49(\mathrm{~m}, 1 \mathrm{H}) ;{ }^{13} \mathrm{C}$ NMR $(100 \mathrm{MHz}$, $\left.\mathrm{CDCl}_{3}\right) \delta 24.7,25.6,67.0,76.8,105.0,114.4,120.6,122.9$, 129.4, 135.9, 138.5, 158.7, 158.8; IR (ZnSe) 513, 693, 757, 1052, 1249, 1499, $1602 \mathrm{~cm}^{-1}$; HRMS $\left(\mathrm{M}^{+}\right)$Found: 259.1203, Calcd for $\mathrm{C}_{14} \mathrm{H}_{15} \mathrm{NO}_{2}: 259.1208$.

Method B: To a solution of $N$-hydroxy-2-pyridone (9, 56 mg, $0.5 \mathrm{mmol})$, 3-phenyl-1-propanol (103 $\mu \mathrm{L}, 0.75 \mathrm{mmol})$ and triphenylphosphine (144 mg, $0.55 \mathrm{mmol})$ in THF (1 $\mathrm{mL})$ was added diethyl azodicarboxylate $(0.1 \mathrm{~mL}, 0.55$ $\mathrm{mmol})$ in $\mathrm{THF}(1 \mathrm{~mL})$ at $0{ }^{\circ} \mathrm{C}$ under $\mathrm{N}_{2}$. After being stirred for $4 \mathrm{~h}$ at room temperature, the reaction mixture was diluted with water and extracted with ethyl acetate. The organic layer was dried over anhydrous $\mathrm{MgSO}_{4}$, filtered and concentrated under reduced pressure. The residue was purified by silica gel column chromatography (ethyl acetate/ $n$-hexane $=1 / 1)$ to give $N$-(3-phenyl-propoxy)-2-pyridone (5, $\left.\mathrm{RO}=\mathrm{Ph}\left(\mathrm{CH}_{2}\right)_{3} \mathrm{O}, 92 \mathrm{mg}, 81 \%\right) .{ }^{1} \mathrm{H}$ NMR $(300 \mathrm{MHz}$, $\left.\mathrm{CDCl}_{3}\right) \delta 2.04(\mathrm{tt}, J=7.8 \mathrm{~Hz}, 6.5 \mathrm{~Hz}, 2 \mathrm{H}), 2.75(\mathrm{t}, J=7.4$ $\mathrm{Hz}, 2 \mathrm{H}), 4.22(\mathrm{t}, J=6.5 \mathrm{~Hz}, 2 \mathrm{H}), 6.04-6.07(\mathrm{~m}, 1 \mathrm{H}), 6.61-$ $6.65(\mathrm{~m}, 1 \mathrm{H}), 7.16-7.29(\mathrm{~m}, 6 \mathrm{H}), 7.40-7.43(\mathrm{~m}, 1 \mathrm{H}) ;{ }^{13} \mathrm{C}$ NMR (100 MHz, $\left.\mathrm{CDCl}_{3}\right) \delta 29.4,31.8,76.4,105.0,122.9$, 126.0, 128.4, 128.4, 135.8, 138.5, 140.9, 158.7; IR (ZnSe) 703, 754, 1540, 1669, $1965 \mathrm{~cm}^{-1}$; HRMS $\left(\mathrm{M}^{+}\right)$Found: 229.1111, Calcd for $\mathrm{C}_{14} \mathrm{H}_{15} \mathrm{NO}_{2}$ : 229.1103.

General procedure for the generation of alkoxyl radicals from $N$-alkoxy-2-pyridones 5 . A solution of $N$-(3phenyl-propoxy)-2-pyridone $\left(\mathbf{5}, \mathrm{RO}=\mathrm{Ph}\left(\mathrm{CH}_{2}\right)_{3} \mathrm{O}, 34 \mathrm{mg}\right.$, $0.15 \mathrm{mmol}), n-\mathrm{Bu}_{3} \mathrm{SnH}(61 \mu \mathrm{L}, 0.225 \mathrm{mmol})$, and AIBN $(0.5 \mathrm{mg}, 0.03 \mathrm{mmol})$ in dry benzene $(1 \mathrm{~mL}, 0.15 \mathrm{M})$ was degassed for $10 \mathrm{~min}$ with nitrogen. After being refluxed for $6 \mathrm{~h}$ at $80{ }^{\circ} \mathrm{C}$, the reaction mixture was concentrated under reduced pressure. The residue was purified by silica gel column (ethyl acetate $/ n$-hexane $=1 / 2$ ) to give 3 -phenyl-1propanol (15, $\left.\mathrm{RO}=\mathrm{Ph}\left(\mathrm{CH}_{2}\right)_{3} \mathrm{O}, 16.9 \mathrm{mg}, 83 \%\right)$.

Acknowledgment. We thank the Center for Molecular Design and Synthesis (CMDS) and BK21 program for financial support.

\section{References}

1. (a) Kochi, J. In Free Radicals; Kochi, J., Ed.; Wiley: New York, 1973; Vol. 2, Ch. 24. (b) Beckwith, A. L. J.; Ingold, K. U. In Rearrangements in Ground and Excited States; de Mayo, P., Ed.; Academic: New York, 1980; Vol. 1, pp 161-309. (c) Ramaiah, M.
Tetrahedron 1987, 43, 3541. (d) Suarez, E.; Rodriguez, M. S Radicals in Organic Synthesis; Renaud, P., Sibi, M. P., Eds.; Wiley-VCH: Weinheim, 2001; Vol. 2, pp 440-454, Ch. 5.3. (e) Hartung, J.; Gottwald, T.; Spehar, K. Synthesis 2002, 1469. (f) Kim, S.; Cho, C. H.; Lim, C. J. J. Am. Chem. Soc. 2003, 125, 9574.

2. (a) Majetich, G.; Wheless, K. Tetrahedron 1995, 51, 7095. (b) Feray, L.; Kuznetsov, N.; Renaud, P. Radicals in Organic Synthesis; Renaud, P., Sibi, M. P., Eds.; Wiley-VCH: Weinheim, 2001; Vol. 2, pp 246-278, Ch. 3.6. (c) Cekovic, Z. Tetrahedron 2003, 59, 8073 .

3. (a) Barton, D. H. R.; Beaton, J. M.; Geller, L. E.; Pechet, M. M. J. Am. Chem. Soc. 1960, 82, 2640. (b) Akhtan, M. Adv. Photochem. 1964, 2, 263.

4. (a) Beckwith, A. L. J.; Schiesser, C. H. Tetrahedron 1985, 41, 3925. (b) Vite, G. D.; Fraser-Reid, B. Synth. Commun. 1988, 18, 1339 .

5. (a) Kraus, G. A.; Thurston, J. Tetrahedron Lett. 1987, 28, 4011. (b) Furuta, K.; Nagata, T.; Yamamoto, H. Tetrahedron Lett. 1988, 29, 2215. (c) Suginome, H.; Wang, J. B. J. Chem. Soc., Perkin Trans. 1 1990, 2825. (d) Inanaga, J.; Sugimoto, Y.; Yokoyama, Y; Hanamoto, T. Tetrahedron Lett. 1992, 33, 8109.

6. (a) Beckwith, A. L. J.; Hay, B. P.; Williams, G. M. J. Chem. Soc., Chem. Commun. 1989, 1202. (b) Pasto, D. J.; L'Hermine, G. $J$. Org. Chem. 1990, 55, 5815. (c) Pasto, D. J.; Cottard, F. Tetrahedron Lett. 1994, 35, 4303.

7. (a) Kim, S.; Lee, T. A.; Song, Y. Synlett 1998, 471. (b) Crich, D.; Huang, X.; Newcomb, M. Org. Lett. 1999, 1, 225. (c) Crich, D.; Huang, X.; Newcomb, M. J. Org. Chem. 2000, 65, 523.

8. For other alkoxyl radical precursors, see: (a) Hartung, J. Radicals in Organic Synthesis; Renaud, P., Sibi, M. P., Eds.; Wiley-VCH: Weinheim, 2001; Vol. 2, pp 427-439, Ch. 5.2. (b) Kim, S.; Lee, T. A. Synlett 1997, 950. (c) Kim, S.; Lim, C. J.; Song, S.-E.; Kang, H.-Y. Synlett 2001, 688. (d) Hartung, J.; Thomas, G.; Kristina, S. Synlett 2003, 227.

9. (a) Beckwith, A. L. J.; Hay, B. P. J. Am. Chem. Soc. 1988, 110, 4415. (b) Beckwith, A. L. J.; Hay, B. P. J. Am. Chem. Soc. 1989, $111,230$.

10. Hay, B. P.; Beckwith, A. L. J. J. Org. Chem. 1989, 54, 4330.

11. (a) Hartung, J. Synlett 1996, 1206. (b) Hartung, J.; Kneuer, R.; Schwarz, M.; Svoboda, I.; Fueb, H. Eur. J. Org. Chem. 1999, 97. (c) Hartung, J. Eur. J. Org. Chem. 2001, 619.

12. (a) Adam, W.; Marquardt, S.; Kemmer, D.; Saha-Moller, C. R.; Schreier, P. Photochem. Photobiol. Sci. 2002, 1, 609. (b) Adam, W.; Hartung, J.; Okamoto, H.; Marquardt, S.; Nau, W. M.; Pischel, U.; Saha-Moller, C. R.; Spehar, K. J. Org. Chem. 2002, 67, 6041 .

13. (a) Sakurai, T.; Kubo, K.; Kojima, S.; Shoro, T.; Inoue, H. Tetrahedron Lett. 1998, 39, 9747. (b) Yoshioka, N.; Andoh, C.; Kubo, K.; Igarashi, T.; Sakurai, T. J. Chem. Soc., Perkin Trans. 2 2001, 1927.

14. Barton, D. H. R.; Blundell, P.; Jaszberenyi, J. Cs. Tetrahedron Lett. 1989, 30, 2341.

15. For our recent reports, (a) Kim, S.; Lim, C. J. Bull. Korean Chem. Soc. 2003, 24, 1219. (b) Lee, S.; Lim, C. J.; Kim, S. Bull. Korean Chem. Soc. 2004, 25, 1611

16. (a) Katritzky, A. R. J. Chem. Soc. 1957, 191. (b) Gardner, J. N.; Katritzky, A. R. J. Chem. Soc. 1957, 4375. (c) Paquette, L. A. J. Am. Chem. Soc. 1965, 87, 5186. 